\title{
Dental pain prevalence associated with caries experience in pediatric patients in a clinical sample in Mexico
}

César Tadeo HERNÁNDEZ-MARTíNEZ(a) Sandra Isabel JIMÉNEZ-GAYOSSO(a) Salvador Eduardo LUCAS-RINCÓN(a) Norma Leticia ROBLES-BERMEO(b) Nuria PATIÑO-MARÍN(c) Juan José VILLALOBOS-RODELO(d) (i) Carlo Eduardo MEDINA-SOLÍS(a) (D) Gerardo MAUPOMÉ(e)

(a)Autonomous University of Hidalgo State UAEH, Health Sciences Institute, Academic Area of Dentistry, Pachuca, HG, México.

(b)Autonomous University of the State of Mexico - UAEM, School of Dentistry, Advanced Studies and Research Center in Dentistry "Dr. Keisaburo Miyata", Toluca, EM, México.

(c)Autonomous University of San Luis Potosí - UASLP, School of Dentistry, Doctoral Program in Dental Sciences, San Luis Potosí, SL, México.

(d) Institute of Social Security and Services Government Workers - ISSSTE, Department of Epidemiology, Culiacan, SI, Mexico.

(e) Indiana University, Richard M. Fairbanks School of Public Health, Indianapolis, IN, USA

Declaration of Interests: The authors certify that they have no commercial or associative interest that represents a conflict of interest in connection with the manuscript.

\section{Corresponding Author:}

Carlo Eduardo Medina-Solís

E-mail: cemedinas@yahoo.com

hitps://doi.org/10.1590/1807-3107bor-2021.vol35.0076

Submitted: August 8, 2020

Accepted for publication: February 3, 2021

Last revision: February 17, 2021
Abstract: The aim of this study was to identify if the prevalence of dental pain (past and / or present) is associated with caries experience in Mexican children, as well as to characterize factors associated with dental pain. A cross-sectional study was conducted in a consecutive sample of 309 children 2 to 12 years old who were patients at a dental school clinic in Toluca, Mexico. Data were collected from clinical records. The dependent variable had three categories: $0=$ have never had dental pain, 1 = had dental pain before the appointment, and $2=$ current dental pain. Non-parametric statistical tests were used in the analysis. A multivariate multinomial logistic regression model was generated in Stata 11.0. Average age was $5.71 \pm 2.43$ years and 50.8\% were boys. The joint $\mathrm{dmft}+\mathrm{DMFT}$ index was $9.11 \pm 4.19$. It was observed that $56.6 \%$ of children did not report having experienced dental pain, $30.7 \%$ reported having previously had dental pain, and $12.6 \%$ had pain when the clinical appointment took place. In the multivariate model, variables associated $(p<.05)$ with previous dental pain were age $(\mathrm{OR}=1.13)$; the $\mathrm{dmft}+\mathrm{DMFT}$ index $(\mathrm{OR}=1.13)$, having had a last dental visit for curative/emergency reasons $(\mathrm{OR}=2.41)$ and prior experience of dental trauma $(\mathrm{OR}=2.59)$. For current pain, only the joint $\mathrm{dmft}+\mathrm{DMFT}$ index $(\mathrm{OR}=1.10, \mathrm{p}<0.05)$ had significant associations. Almost half of the children had experienced dental pain in their lifetime. Since caries experience is a factor associated with dental pain, decreasing caries levels may ameliorate suffering from dental pain in children.

Keywords: Oral Health; Child Health; Pain; Dental Caries; Epidemiology.

\section{Introduction}

Pain is considered a normal consequence of organ or system disorders. According to the International Association for the Study of Pain, ${ }^{1}$ it is an unpleasant sensory and emotional experience that promotes changes in behavior, which often hinders daily activities. Dental pain has been defined as pain originating from innervated tissues within the tooth (pulp) or immediately adjacent tissues (periodontal) as a consequence of caries, periodontal disease, trauma, occlusal dysfunction or abscess. ${ }^{2,3}$ This condition can affect daily life in the short, medium and long terms. Dental pain among children, adolescents and adults has been identified as 
a public health problem, ${ }^{3}$ being a relatively common symptom of dental diseases -- particularly untreated carious lesions. ${ }^{4}$

Caries in primary and permanent dentitions is one of the main oral public health problems and one of the most pressing treatment needs in children and adolescents both in Mexico ${ }^{5}$ and in the world. ${ }^{6}$ In Mexico, caries prevalence in permanent dentition ranged from 70 to $85 \%$ among 12 -year-old schoolchildren until before $2000 .^{7}$ For the primary dentition, $\mathrm{dmft}$ values between 0.73 and 5.35 have been reported in 6-year-old children, with a prevalence between $26.3 \%$ and $77.5 \%$. DMFT index at the age of 12 ranged between 0.52 and 3.67, with a prevalence between $30.7 \%$ and $79.2 \%{ }^{5}$ In a large percentage of children (between $81.7 \%$ and $99.5 \%$ ), high treatment needs were present in primary teeth; this percentage was between $55.4 \%$ and $93.4 \%$ in permanent dentition. ${ }^{5}$

A previous review for children and adolescents global health found dental pain prevalence between 5 and $33 \%$. The lifetime prevalence was higher among older children and children from lower socioeconomic groups. ${ }^{8}$ A more recent review pointed to a prevalence of dental pain from 1.33 to $87.8 \%$ in children up to 18 years of age. ${ }^{9}$ Although not all children with caries reported pain or an impact on their quality of life related to oral health, both caries and dental pain have been identified generally as negative impacts on the quality of life in children. ${ }^{8,10}$ Among factors associated with dental pain in both developed and developing countries are demographic, socioeconomic, family, psychosocial and cultural issues, as well as oral health status. ${ }^{11}$ Recommendations from both the World Health Organization and the International Dental Federation include amelioration of dental pain as a priority goal in the International Agenda for the Oral Health Promotion. ${ }^{12}$ However, in Mexico there are few epidemiological studies about dental pain. ${ }^{13,14}$ The objective of the present study was to identify whether dental pain prevalence (past and / or present) was associated with caries experience in Mexican children, as well as to characterize the factors associated with pain. Our hypothesis was that school children with caries experience in primary and/or permanent teeth were at higher risk to having dental pain (past and / or present).

\section{Methodology}

\section{Study design, population and sample}

A retrospective cross-sectional study was conducted in patients 2 to 12 years old. The present report is part of a project in which multiple oral health indicators were measured. The methodology about data on dental caries and dental trauma has been reported previously, ${ }^{15,16}$ and it is summarized below. Sample size calculation was performed with a confidence level of $95 \%$, an accuracy of $4 \%$, a proportion (approximate value of the parameter) of $90 \%$ and an expected loss ratio of $10 \%$, resulting in 314 individuals. Inclusion criteria were: a) both sexes; b) from 2 to 12 years; $\mathrm{c}$ ) children living in the community (i.e., not institutionalized). The final sample were 309 records of patients at the dental clinic of the Autonomous University of the State of Mexico. This clinic is located in Toluca de Lerdo, capital of the State of Mexico, and its home base is the state's public university. It provides specialty services at low cost to the general population, with most patients having low to medium socioeconomic level. In Mexico, specialty services encompass pediatric dentistry, orthodontics, endodontics, periodontics, prosthodontics, etc.

\section{Brief description of the Mexican dental health care system}

The Mexican health system is complex; dental care reaches the open population a) through publicly funded agencies for employees and their household members, and some coverage for those who are selfemployed and their families. These agencies rarely offer specialty care, which is largely within the domain of b) private dental offices. Private dental insurance is uncommon, and most of these treatment courses are paid with out of pocket costs at point of service. c) A small number of patients are covered by clinics funded by the Army, Navy and the large state-owned oil company (Petróleos Mexicanos). Clinical care in such sub-systems is usually more comprehensive than publicly-funded options. Finally, 4) a large number of dental schools $(n=150+)$ have 
dental clinics staffed by dental students and faculty. Services often encompass specialty care, with costs substantially lower than private dental practice. ${ }^{17}$

\section{Data collection}

Data were obtained from records previously filled with information supplied by parents / guardians of patients. The dependent variable was: dental pain experience before the appointment $(0=$ No, $1=$ Yes $)$, and presence of dental pain at the time of appointment $(0=$ No, $1=$ Yes). The variable had three categories: $0=$ have never had dental pain, $1=$ dental pain before the appointment but not currently, and $2=$ current dental pain (Table 1).

The independent variables included in the study were: age (from 2 to 12 years old), number of siblings, tooth brushing frequency per day, sex $(0=$ boy, $1=$ girl $)$, reason for the last dental visit $(0=$ Preventive, $1=$ Curative $/$ Emergency) and dental trauma experience $(0=$ No, $1=$ Yes). Caries experience was also included for each dentition. The $\mathrm{dmft}$ index (decay, missing/indicated for extraction and filled teeth in the primary dentition) and DMFT index (decay, missing and filled teeth in the permanent

Table 1. Descriptive analysis of the independent variables.

\begin{tabular}{lcc}
\hline Variable & Mean & SD \\
\hline Child's age & 5.71 & 2.43 \\
Number of siblings & 1.37 & 1.03 \\
Tooth brushing frequency & 2.71 & 0.71 \\
dmft index $(n=306)$ & 8.53 & 4.18 \\
DMFT index $(n=107)$ & 1.91 & 2.02 \\
dmft + DMFT ( $n=309)$ & 9.11 & 4.19 \\
& Frequency & Percentage \\
Sex & & \\
Boy & 157 & 50.8 \\
Girl & 152 & 49.2 \\
Reason for the last dental visit & & \\
Preventive & 62 & 20.1 \\
Curative / Emergency & 247 & 79.9 \\
Dental trauma & & \\
No & 272 & 12.0 \\
Yes & 37 & \\
\hline
\end{tabular}

dentition) were calculated; these indices represent past and present experience of caries through its components. The indices were obtained from the clinical records.

There is a caveat in our approach to data management. With children spanning in age from 2 to 12 , we had 109 with only permanent dentition, 306 with only primary, and 104 with mixed dentition. We conducted statistical models with separate $\mathrm{dmft}$ or DMFT, but only 104 children had data pertaining to both dentitions. Without having an ideal solution for this age group ( 2 to 12 years of age), we created a joint measure ( $\mathrm{dmft}+\mathrm{DMFT})$ that is relevant to the experience of dental pain - regardless of being permanent or primary teeth.

\section{Statistical analysis}

In the univariate analysis, frequencies and percentages were reported for qualitative variables, as well as means and standard deviation for quantitative variables.

In the bivariate analysis, non-parametric statistical tests were performed: Kruskall-Wallis, Chi-square and Fisher's exact tests. Because our dependent variable involved three categories, a multivariate multinomial logistic regression model was constructed. The strength of associations between dependent and independent variables is presented as odds ratios (ORs) with 95\% confidence intervals (CI). P values were considered statistically significant at $<0.05$.

For construction of the final model, variables that had a statistical significance of $p<0.25$ were taken into account in the bivariate analysis. The variance inflation factor test (VIF) was performed in order to analyze, and where appropriate, avoid multicollinearity between the independent variables. The overall fit of the model was established with a goodness-of-fit test. Stata 11.0 statistical package was used to perform data analysis.

\section{Ethical considerations}

The present study was undertaken following regulations for health research on human participants (General Health Law on Research in force in Mexico) and the Declaration of Helsinki. Parents/guardians approved data being used for research. The protocol 
was approved at the School of Dentistry, Autonomous University of the State of Mexico.

\section{Results}

A total of 309 dental records were reviewed. Average age was $5.71 \pm 2.43$ years and $50.8 \%$ were boys. Most participants, 175 (56.6\%), reported not having experienced dental pain; but $30.7 \%$ $(\mathrm{n}=95)$ reported having previously had dental pain, and $12.6 \%(n=39)$ had pain at the time of the appointment. We observed that $6.1 \%(\mathrm{n}=19)$ had both previous and current dental pain. Table 1 shows the results of univariate analyses. $\mathrm{dmft}$ index was $8.53 \pm 4.18$, which was calculated for 306 children who had at least one primary tooth. The DMFT index was $1.91 \pm 2.02$, which was calculated for 107 children who had at least one permanent tooth. $\mathrm{dmft}+\mathrm{DMFT}$ index was $9.11 \pm 4.19$. In the sample, $20.1 \%$ had a preventive dental reason for their last visit to the dentist, and $12 \%$ reported having had dental trauma.
Table 2 presents results of the bivariate analysis between dental pain and independent variables. Joint caries indices showed an association $(p<0.05)$ with dental pain; it was low in those who had never experienced dental pain. Likewise, significant differences were observed across the reason for the last dental appointment $(p<0.001)$ and with previous dental trauma $(\mathrm{p}<0.05)$.

The multivariate model of multinomial logistic regression is in Table 3. For previous dental pain, it was observed that for each year of age the odds of presenting dental pain increased 13\% (95\%CI $=1-27)$. For each unit increasing in the joint $\mathrm{dmft}+\mathrm{DMFT}$ index, the likelihood of having dental pain increased 13\% $(95 \% \mathrm{CI}=6-20)$. In those children whose last dental visit was for curative / emergency reasons, they were $2.41(95 \% \mathrm{CI}=1.18-4.93)$ times more likely to have dental pain than children whose last visit was for preventive reasons. Children with dental trauma had greater odds $(\mathrm{OR}=2.59 ; 95 \% \mathrm{CI}=1.17-5.69)$ of having had pain than children without dental trauma. In the case of currently experienced pain (i.e., at the time

Table 2. Bivariate analysis of dental pain and the independent variables.

\begin{tabular}{|c|c|c|c|c|}
\hline \multirow{2}{*}{ Variable } & Without pain & Pain previously & Pain currently & \multirow{2}{*}{ p-value } \\
\hline & $(n=175)$ & $(n=95)$ & $(n=39)$ & \\
\hline Child's age & $5.46 \pm 2.42$ & $6.06 \pm 2.40$ & $6.00 \pm 2.54$ & $0.0973^{*}$ \\
\hline Number of siblings & $1.28 \pm 1.00$ & $1.44 \pm 1.05$ & $1.59 \pm 1.12$ & $0.1283^{*}$ \\
\hline Tooth brushing frequency & $2.70 \pm 0.75$ & $2.69 \pm 0.64$ & $2.85 \pm 0.74$ & $0.5769^{*}$ \\
\hline dmft index ${ }^{a}$ & $7.98 \pm 4.31$ & $9.44 \pm 3.89$ & $8.81 \pm 3.91$ & $0.0115^{*}$ \\
\hline DMFT index ${ }^{b}$ & $1.40 \pm 1.78$ & $2.40 \pm 2.11$ & $2.53 \pm 2.23$ & $0.0342^{*}$ \\
\hline$d m f t+D M F T^{c}$ & $8.37 \pm 4.47$ & $10.27 \pm 3.53$ & $9.56 \pm 3.73$ & $0.0004^{*}$ \\
\hline \multicolumn{5}{|l|}{ Sex } \\
\hline Boy & $88(56.0)$ & $54(34.4)$ & $15(9.6)$ & \\
\hline Girl & $87(57.2)$ & $41(27.0)$ & $24(15.8)$ & $0.151^{* *}$ \\
\hline \multicolumn{5}{|c|}{ Reason for the last dental visit } \\
\hline Preventive & $49(79.0)$ & $13(21.0)$ & $0(0.0)$ & \\
\hline Curative / Emergency & $126(51.0)$ & $82(33.2)$ & $39(15.8)$ & $<0.001^{* * *}$ \\
\hline \multicolumn{5}{|l|}{ Dental trauma } \\
\hline No & $160(58.8)$ & $77(28.3)$ & $35(12.9)$ & \\
\hline Yes & $15(40.5)$ & $18(48.6)$ & $4(10.8)$ & $0.040^{* *}$ \\
\hline
\end{tabular}

${ }^{*}$ Kruskall-Wallis test, ${ }^{* *}$ Chi square test, ${ }^{* * *}$ Fisher's exact test. ${ }^{\circ}$ Multiple comparisons between groups $\mathrm{dmft}: 1$ vs $2, p=0.0016 ; 1$ vs 3 , $p=0.1204 ; 2$ vs 3, $p=0.1924 ;{ }^{b}$ Multiple comparisons between groups DMFT: 1 vs $2, p=0.0180 ; 1$ vs 3, $p=0.0285 ; 2$ vs 3, $p=0.3615$; Multiple comparisons between groups dmft+DMFT: 1 vs $2, p<0.0001 ; 1$ vs $3, p=0.0455 ; 2$ vs $3, p=0.1564$. 
Table 3. Multivariate analysis of dental pain and the independent variables.

\begin{tabular}{|c|c|c|c|c|}
\hline \multirow{2}{*}{ Variable } & Pain previously & \multirow{2}{*}{$\mathrm{p}$-value } & Pain currently & \multirow{2}{*}{$\mathrm{p}$-value } \\
\hline & OR 95\%Cl & & OR 95\%Cl & \\
\hline Child's age & $1.13(1.01-1.27)$ & 0.028 & $1.07(0.92-1.24)$ & 0.393 \\
\hline $\mathrm{dmft}+\mathrm{DMFT}$ & $1.13(1.06-1.20)$ & $<0.001$ & $1.10(1.00-1.20)$ & 0.044 \\
\hline \multicolumn{5}{|c|}{ Reason for the last dental visit } \\
\hline Preventive & $1^{*}$ & & $1^{*}$ & \\
\hline Curative / Emergency & $2.41(1.18-4.93)$ & 0.016 & - & 0.979 \\
\hline \multicolumn{5}{|l|}{ Dental trauma } \\
\hline No & $1^{*}$ & & $1^{*}$ & \\
\hline Yes & 2.59 (1.17-5.69) & 0.018 & $1.26(0.37-4.27)$ & 0.709 \\
\hline
\end{tabular}

Sex-adjusted estimates Goodness-of-fit test X2 $=21.097, p=0.170$

*Reference category

of the appointment), for each unit increasing in the joint dmf + DMFT index, the likelihood of having dental pain increased $10 \%(\mathrm{p}<0.05)$.

\section{Discussion}

We found $43.4 \%$ dental pain prevalence (previous and current). Dental caries experience was an associated factor, in addition to child age, reason for last dental visit, and dental trauma experience. Dental pain is considered a public health problem due to negative impacts in society, high costs of treatment, and consequences such as school absenteeism, use of medications, and children emotional and social discomfort. ${ }^{18}$ In a previous study in Mexico in children 6 to 12 years old, a $49.9 \%$ dental pain prevalence was reported, ${ }^{13}$ which is higher than our results. Other countries such as Brazil have observed prevalence up to $51.5 \% .^{18}$ In India, prevalence was $35 \%,{ }^{19}$ in Sri Lanka between $49 \%$ to $53 \%{ }^{20}$ Higher values have been reported in other countries such as South Africa $(70 \%)^{21}$ or Nigeria $(84.5 \%) .{ }^{22}$ These reports suggest that prevalence of dental pain around the world makes up a vast mosaic of values. Such differences may be attributed to various factors. Among them, the socio-economic development level in different countries (and by implication, access to industrialized food/beverages with high added sugar content, and/or availability of dental services), variations in disease levels across and within populations, health systems' ability to meet oral health needs, age of subjects, and the year and methodologies used across studies. ${ }^{13}$ Such considerable diversity constrains a complete discussion of our findings, including a shortcoming in our study of using a research population actively seeking dental care.

Caries experience was a variable associated with dental pain in our study population. Prevalence of dental pain increased in association with the combined dental indices; the number of affected teeth was associated with both previous and current pain. Although a reduction in caries prevalence in Mexico has been observed in recent decades, ${ }^{23,24}$ a large percentage of the population still has high treatment needs in both primary and permanent dentition. These can be almost $100 \%$ in some regions. ${ }^{5}$ This landscape suggests that dental pain and caries may be common among Mexican schoolchildren. Against a background where caries is known to be the main triggering factor for dental pain, ${ }^{4,8,19,25}$ school children with higher $\mathrm{dmft}+$ DMFT indices had increased dental pain experience, with such findings being consistent with reports from other parts of the world. These findings must be considered in the context of reduced access to dental services (preventive and curative).

Individual level variables explained most of the variation in dental pain. This is expected, as demographic characteristics may only modify social contexts but biological mechanisms may be directly increasing dental pain risk; for example, physiologic differences between men and women could play a 
role in pain perception. ${ }^{26}$ In the present study, no sex differences were observed in children ages 3 to 12 years, in agreement with previous reports. ${ }^{26,27}$ However, in older children, increased socialization and establishment of cultural rules and patterns may explain lower prevalence of dental pain in males. ${ }^{28} \mathrm{In}$ our study, boys seemed to have a higher prevalence of previous pain, and girls seemed to have a higher prevalence of current pain, with differences being not significant. With regard to age, we observed that older children had higher experience of previous dental pain. ${ }^{11,25}$ This is not surprising, since older children are more likely to have more untreated carious lesions in Mexico. ${ }^{5}$ However, this trend did not hold when age and current dental pain were examined. It is important to point that most studies in children are based on previous pain experience (within the last month, six or 12 months), not current pain.

Mexico is a middle-income country where the majority of the population, especially children and adolescents, have limited access to preventive and curative dental health services. ${ }^{17,29}$ This happens against an epidemiological landscape where caries prevalence is high and many lesions are not treated. ${ }^{5}$ Results of the present study revealed a positive association between the reason for appointment (curative / emergency) and dental pain as factors more strongly associated with previous pain. Dental pain in children could be avoided and quality of life improved through the strengthening of preventive and therapeutic dental programs and services for children. ${ }^{30}$ Brazilian data showed that children who sought dental care for current pain reported pain in the previous six months. ${ }^{4}$ In the present study we also observed that previous dental pain was associated with dental trauma. Dental trauma is associated with pain, bleeding, dental mobility, tooth loss, low self-esteem, and post-traumatic stress / anxiety. ${ }^{31}$ They are more frequent during the first 10 years of life, gradually decrease with age, and are very rare after age $30 .{ }^{32}$ Interestingly, both the reason for appointment (curative / emergency) and presence of dental trauma were only associated with previous dental pain but not with current dental pain.

Despite obvious strengths in the present study (e.g., having scrutinized associations with more finely grained types of dental pain) there are some limitations in our research design. For example, its retrospective cross-sectional design limits establishing causal relationships, thereby presenting the problem of temporal ambiguity. We documented variables using data collected from clinical records filled by parents or guardians of patients who were seeking dental care. Because parents reported dental pain, actual perceptions by children might not have always been accurately represented. Moreover, different clinicians administered intake questionnaires; variation may have resulted from a range of perspectives involved. Although reasonable, we assumed that experience of pain was linked to caries experience; ${ }^{4,8,89,25}$ this is a common linkage but it is not absolute. Another limitation was that we did not analyze the relationship between socioeconomic indicators and the outcome variable; however, prior research supports the assertion that the population seeking clinical care in this environment share largely homogeneous socioeconomic characteristics. ${ }^{28,29}$

\section{Conclusion}

We conclude that almost half of the children in this study have experienced dental pain in their lifetime. Caries experience was a factor associated with experience of dental pain in the child population. Preventing and treating caries will decrease the likelihood of its impacts on children. Caries continues to be a health problem, with dentists play a leading role in its prevention and treatment.

\section{References}

1. Merskey H, Bogduk N. Task force on taxonomy. part iii: pain terms, a current list with definitions and notes on usage. Seattle: IASP Press; 1994.

2. Pau AK, Croucher R, Marcenes W. Prevalence estimates and associated factors for dental pain: a review. Oral Health Prev Dent. 2003;1(3):209-20. https://doi.org/10.3290/i.ohpd.a8529 
Hernández-Martínez CT, Jiménez-Gayosso SI, Lucas-Rincón SE, Robles-Bermeo NL, Patiño-Marín N, Villalobos-Rodelo JJ, et al.

3. Pau A, Viswanath KP, Croucher R. Validation of a dental pain screening questionnaire in a semi-urban hospital setting in South India. Int Dent J. 2010 Apr;60(2):113-21. https://doi.org/10.1922/IDJ_2332Pau09

4. Guskuma RC, Lages VA, Hafner MB, Rando-Meirelles MP, Cypriano S, Sousa MD, et al. Factors associated with the prevalence and intensity of dental pain in children in the municipalities of the Campinas region, São Paulo. Rev Paul Pediatr. 2017 Jul-Sep;35(3):322-30. https://doi.org/10.1590/1984-0462/;2017;35;3;00001

5. Medina-Solís CE, Ávila-Burgos L, Borges-Yañez SA, Irigoyen-Camacho ME, Sánchez-Pérez L, Zepeda-Zepeda MA, et al. Ecological study on needs and cost of treatment for dental caries in schoolchildren aged 6, 12, and 15 years: data from a national survey in Mexico. Medicine (Baltimore). 2020 Feb;99(7):e19092. https://doi.org/10.1097/MD.0000000000019092

6. Kassebaum NJ, Bernabé E, Dahiya M, Bhandari B, Murray CJ, Marcenes W. Global burden of untreated caries: a systematic review and metaregression. J Dent Res. 2015 May;94(5):650-8. https://doi.org/10.1177/0022034515573272

7. Medina-Solis CE, Maupomé G, Pérez-Núñez R, Avila-Burgos L, Pelcastre-Villafuerte B, Pontigo-Loyola AP. [Oral health policy in Mexico: reducing the principal diseases: a description]. Rev Biomed. 2006;17(4):269-86. Spanish. https://doi.org/10.32776/revbiomed.v17i4.466

8. Slade GD. Epidemiology of dental pain and dental caries among children and adolescents. Community Dent Health. 2001 Dec;18(4):219-27.

9. Pentapati KC, Yeturu SK, Siddiq H. Global and regional estimates of dental pain among children and adolescents-systematic review and meta-analysis. Eur Arch Paediatr Dent. 2020 Jun 16. https://doi.org/10.1007/s40368-020-00545-7. Epub ahead of print.

10. Barasuol JC, Santos PS, Moccelini BS, Magno MB, Bolan M, Martins-Júnior PA, et al. Association between dental pain and oral health-related quality of life in children and adolescents: a systematic review and meta-analysis. Community Dent Oral Epidemiol. 2020 Aug;48(4):257-63. https://doi.org/10.1111/cdoe.12535

11. Freire MC, Nery NG, Jordão LM, Abreu MH. Individual and contextual determinants of dental pain in adolescents: evidence from a national survey. Oral Dis. 2019 Jul;25(5):1384-93. https://doi.org/10.1111/odi.13100

12. Hobdell M, Petersen PE, Clarkson J, Johnson N. Global goals for oral health 2020. Int Dent J. 2003 Oct;53(5):285-8. https://doi.org/10.1111/j.1875-595X.2003.tb00761.x

13. Escoffié-Ramirez M, Ávila-Burgos L, Baena-Santillan ES, Aguilar-Ayala F, Lara-Carrillo E, Minaya-Sánchez $M$, et al. Factors associated with dental pain in Mexican schoolchildren aged 6 to 12 years. BioMed Res Int. 2017;2017:7431301. https://doi.org/10.1155/2017/7431301

14. García-Cortés JO, Mariel-Cárdenas J, Martínez-Rider R, Islas-Zarazúa R, de la Rosa-Santillana R, Navarrete-Hernández JJ, et al. Dental pain and associated factors in Mexican adolescents and young adults: a cross-sectional study. Int Dent J. 2020 Dec;70(6):455-61. https://doi.org/10.1111/idj.12598

15. Garibay-Martínez AK, Robles-Bermeo NL, Hernández-Martínez CT, Guadarrama-Quiroz LJ, Pedraza-Contreras G, Jiménez-Gayosso $\mathrm{SI}$, et al. [Dental trauma in pediatric patients consulting at a university pediatric dentistry clinic: a retrospective analysis of medical records]. Pediatría (Asunción). 2018;45(3):206-11. Spanish. https://doi.org/10.31698/ped.45032018003

16. Hernández-Martínez CT, Robles-Bermeo NL, Lara-Carrillo E, Medina-Solís CE, Jiménez-Gayosso SI, Pontigo-Loyola AP, et al. Factors associated with dental caries in primary and permanent dentition in patients aged 2 to 12 years who attended a university clinic. West Indian Med J. Forthcoming 2017 Aug. https://doi.org/10.7727/wimi.2017.120

17. Cerón-Zamora E, Navarrete-Hernández JJ, Lara-Carrillo E, Robles-Bermeo NL, Lucas-Rincón SE, Hernández-Martínez CT, et al. Factors associated with the use of Dental Health Services by Mexican Schoolchildren to receive Professionally Applied Topical Fluoride. P R Health Sci J. 2020 Jun;39(2):203-9.

18. Santos PS, Martins-Júnior PA, Paiva SM, Klein D, Torres FM, Giacomin A, et al. Prevalence of self-reported dental pain and associated factors among eight- to ten-year-old Brazilian schoolchildren. PLoS One. 2019 Apr;14(4):e0214990. https://doi.org/10.1371/journal.pone.0214990

19. Kumar YS, Acharya S, Pentapati KC. Prevalence of dental pain and its relationship to caries experience in school children of Udupi district. Eur Arch Paediatr Dent. 2014 Dec;15(6):371-5. https://doi.org/10.1007/s40368-014-0124-1

20. Ratnayake N, Ekanayake L. Prevalence and impact of oral pain in 8-year-old children in Sri Lanka. Int J Paediatr Dent. 2005 Mar;15(2):105-12. https://doi.org/10.1111/i.1365-263X.2005.00602.x

21. Naidoo S, Chikte UM, Sheiham A. Prevalence and impact of dental pain in 8-10-year-olds in the western Cape. SADJ. 2001 Nov;56(11):521-3.

22. Azodo CC, Ogordi PU. Pain-related pediatric dental attendance in a Nigerian dental clinic. J Oral Res Rev. 2016;8(1):6-11. https://doi.org/10.4103/2249-4987.182489

23. Irigoyen ME, Sánchez-Hinojosa G. Changes in dental caries prevalence in 12-year-old students in the State of Mexico after 9 years of salt fluoridation. Caries Res. 2000 Jul-Aug;34(4):303-7. https://doi.org/10.1159/000016606

24. Irigoyen ME, Mejía-González A, Zepeda-Zepeda MA, Betancourt-Linares A, Lezana-Fernández MA, Álvarez-Lucas CH. Dental caries in Mexican schoolchildren: a comparison of 1988-1989 and 1998-2001 surveys. Med Oral Patol Oral Cir Bucal. 2012 Sep;17(5):e825-32. https://doi.org/10.4317/medoral.18008 
Dental pain prevalence associated with caries experience in pediatric patients in a clinical sample in Mexico

25. Adeniyi AA, Odusanya $\bigcirc$. Self-reported dental pain and dental caries among 8-12-year-old school children: an exploratory survey in Lagos, Nigeria. Niger Postgrad Med J. 2017 Jan-Mar;24(1):37-43. https://doi.org/10.4103/npmi.npmi_7_17

26. Bastos JL, Peres MA, Peres KG, Araujo CL, Menezes AM. Toothache prevalence and associated factors: a life course study from birth to age 12 yr. Eur J Oral Sci. 2008 Oct;116(5):458-66. https://doi.org/10.1111/i.1600-0722.2008.00566.x

27. Barrêtto EP, Ferreira EF, Pordeus IA. Determinant factors of toothache in 8- and 9-year-old schoolchildren, Belo Horizonte, MG, Brazil. Braz Oral Res. 2009 Apr-Jun;23(2):124-30. https://doi.org/10.1590/S1806-83242009000200006

28. Boeira GF, Correa MB, Peres KG, Peres MA, Santos IS, Matijasevich A, et al. Caries is the main cause for dental pain in childhood: findings from a birth cohort. Caries Res. 2012;46(5):488-95. https://doi.org/10.1159/000339491

29. Medina-Solís CE, García-Cortés JO, Robles-Minaya JL, Casanova-Rosado JF, Mariel-Cárdenas J, Ruiz-Rodríguez MD, et al. Clinical and non-clinical variables associated with preventive and curative dental service utilisation: a cross-sectional study among adolescents and young adults in Central Mexico. BMJ Open. 2019 Sep;9(9):e027101. https://doi.org/10.1136/bmjopen-2018-027101

30. Locker D, Jokovic A, Stephens M, Kenny D, Tompson B, Guyatt G. Family impact of child oral and oro-facial conditions. Community Dent Oral Epidemiol. 2002 Dec;30(6):438-48. https://doi.org/10.1034/j.1600-0528.2002.00015.x

31. Tewari N, Goel S, Rahul M, Mathur VP, Ritwik P, Haldar P, et al. Global status of knowledge for prevention and emergency management of traumatic dental injuries among school teachers: A systematic review and meta-analysis. Dent Traumatol. 2020 Dec;36(6):568-83. https://doi.org/10.1111/edt.12579

32. Lam R. Epidemiology and outcomes of traumatic dental injuries: a review of the literature. Aust Dent J. 2016 Mar;61 Suppl 1:4-20. https://doi.org/10.1111/adj.12395 